\title{
Effect of bis(maltolato)oxovanadium (IV) (BMOV) on selenium nutritional status in diabetic streptozotocin rats
}

\author{
Cristina Sanchez-Gonzalez ${ }^{1}$, Carmen Bermudez-Peña ${ }^{2}$, Fernando Guerrero-Romero ${ }^{2}$, \\ Cristina E. Trenzado ${ }^{3}$, María Montes-Bayon ${ }^{4}$, Alfredo Sanz-Medel ${ }^{4}$ and Juan Llopis ${ }^{1,5 *}$ \\ ${ }^{1}$ Institute of Nutrition and Food Technology and Department of Physiology, Campus Cartuja, University of Granada, \\ E-18071 Granada, Spain \\ ${ }^{2}$ Biomedical Research Unit, Instituto Mexicano del Seguro Social, Victoria de Durango, Durango, Mexico \\ ${ }^{3}$ Departamento de Biología Animal, Facultad de Ciencias, Campus Fuentenueva, University of Granada, E-18071 Granada, \\ Spain \\ ${ }^{4}$ Department of Analytical Chemistry, University of Oviedo, Oviedo, Spain \\ ${ }^{5}$ Instituto de Nutrición y Tecnología de Alimentos, Centro de Investigaciones Biomédicas, Laboratory 115, Universidad de \\ Granada, Parque Tecnológico de la Salud, 18100 Armilla, Granada, Spain
}

(Submitted 1 August 2011 - Final revision received 12 October 2011 - Accepted 13 October 2011 - First published online 16 November 2011)

\begin{abstract}
The role of $\mathrm{V}$ as a micronutrient, and its hypoglycaemic and toxicological activity, have yet to be completely established. The present study focuses on changes in the bioavailability and tissue distribution of Se in diabetic streptozotocin rats following treatment with V. The following four study groups were examined: control; diabetic (DM); diabetic treated with $1 \mathrm{mg}$ V/d (DMV); diabetic treated with $3 \mathrm{mg}$ $\mathrm{V} / \mathrm{d}$ (DMVH). V was supplied in the drinking water as bis(maltolato)oxovanadium (IV). The experiment had a duration of 5 weeks. Se was measured in food, faeces, urine, serum, muscle, kidney, liver and spleen. Glucose and insulin serum were studied, together with glutathione peroxidase (GSH-Px), glutathione reductase (GR), glutathione transferase (GST) activity and malondialdehyde (MDA) levels in the liver. In the DM group, we recorded higher levels of food intake, Se absorbed, Se retained, Se content in the kidney, liver and spleen, GSH-Px and GST activity, in comparison with the control rats. In the DMV group, there was a significant decrease in food intake, Se absorbed, Se retained and Se content in the liver and spleen, and in GSH-Px and GST activity, while fasting glycaemia and MDA remained unchanged, in comparison with the DM group. In the DMVH group, there was a significant decrease in food intake, glycaemia, Se absorbed, Se retained, Se content in the kidney, liver and spleen, and in GSH-Px and GST activity, and increased MDA, in comparison with the DM and DMV groups. We conclude that under the experimental conditions described, the treatment with 3 mg $\mathrm{V} / \mathrm{d}$ caused a tissue depletion of Se that compromised Se nutritional status and antioxidant defences in the tissues.
\end{abstract}

\section{Key words: Vanadium: Selenium: Diabetes: Nutritional status: Oxidative defence}

Diabetes is a pathology that affects many metabolic processes, altering the concentration of various trace elements in the tissues, and of enzymes related to antioxidant defence. This circumstance, together with the metabolic changes induced by hyperglycaemia, may contribute to the development of the disease.

$\mathrm{V}$ is a widely distributed element, which is essential for some living organisms, but its role as a micronutrient, its essentiality, and its biological and pharmacological activity are as yet incompletely understood. Due to growing interest in the pharmacological effects of some $\mathrm{V}$ compounds, the metabolism of $\mathrm{V}$ is an important area of current investigation $^{(1)}$. In the plasma, $\mathrm{V}$ is present as $90 \%$ bound to plasma proteins, primarily transferrin. Elsewhere, it is distributed primarily in the bone, kidney and liver. However, its interactions with other trace elements, regarding absorption and tissue distribution, are not well understood. Some complexes of $\mathrm{V}$ have been shown to possess hypoglycaemic effects, stimulating autophosphorylation of the insulin receptors and increasing the activity of tyrosine kinase, favouring the translocation of GLUT4 $4^{(1,2)}$. It has been known that the $\mathrm{V}$ complex, bis(maltolato)oxovanadium (IV) (BMOV), is more

Abbreviations: ABTS, 2,2'-azino-di-(3-ethylbenzthiazoline-6-sulfonic acid); BMOV, bis(maltolato)oxovanadium (IV); GR, glutathione reductase; GSH, reduced glutathione; GSH-Px, glutathione peroxidase; GST, glutathione transferase; MDA, malondialdehyde; STZ, streptozotocin; TAS, total antioxidant status.

*Corresponding author: Dr J. Llopis, fax +34958 248959, email jllopis@ugr.es 
effective than inorganic $\mathrm{V}$ as a glucose-lowering agent ${ }^{(1)}$. Although some V complexes are currently undergoing human clinical trials ${ }^{(1)}$, there are many aspects that remain to be determined, such as the digestive and metabolic interactions with other elements involved in antioxidant defence. According to some authors ${ }^{(1-3)}, \mathrm{V}$ improves glucose metabolism, and thus reduces the production of free radicals resulting from disorders in glucose metabolism; in consequence, it prevents oxidant damage caused by diabetes. However, others ${ }^{(4)}$ have related V to pro-oxidant effects, because it does not normalise alterations in the metabolism of various trace elements, such as $\mathrm{Fe}, \mathrm{Zn}$ and $\mathrm{Cu}$, that are associated with diabetes.

In vitro and in vivo studies have shown that sodium selenate has an insulin-mimetic action similar to that of $\mathrm{V}$, and that its administration to diabetic streptozotocin (STZ) rats produces hypoglycaemia ${ }^{(5)}$ by favouring the translocation of GLUT4 transporters in diabetic rats ${ }^{(6)}$. Moreover, Se is an element that is associated with antioxidant defence and protection against heavy metal toxicity ${ }^{(7)}$, a fact also observed in relation to diabetic rats ${ }^{(5,8)}$.

However, to date, no data have been published as to whether exposure to $\mathrm{V}$ might alter the metabolism of Se. For these reasons, we consider it important to address the present study of the interactions between $\mathrm{V}$ and Se in diabetic rats.

The aim of the present study is to examine whether V-treated diabetic rats experience alterations in the bioavailability and tissue distribution of Se, and in the activity of enzymes related to the nutritional status of Se and to antioxidant defence. The results obtained will reveal the existence, or otherwise, of interactions between these two elements and clarify the role of $\mathrm{V}$ as an anti-diabetic agent.

\section{Materials and methods}

\section{Animals and diets}

Male Wistar rats weighing 190-220g (Charles River Laboratories, L'Arbresle, France) were randomly divided into four groups.

(1) Control group (C): nine rats fed the semi-synthetic diet AIN-93. This diet provided $65 \mu \mathrm{g}$ Se and $60 \mu \mathrm{g} \mathrm{V} / \mathrm{kg}$ food.

(2) Diabetic group (DM): eight rats fed the semi-synthetic diet AIN-93. Diabetes was induced in rats by the injection of STZ at a dose of $60 \mathrm{mg} / \mathrm{kg}$.

(3) Diabetic group treated with $1 \mathrm{mg} \mathrm{V} / \mathrm{d}$ (DMV): ten rats fed the semi-synthetic diet AIN-93. Diabetes was induced in rats by the injection of STZ at a dose of $60 \mathrm{mg} / \mathrm{kg}$. In addition, the rats in this group received in their drinking water $6.22 \mathrm{mg} \mathrm{BMOV} / \mathrm{d}$, which supplied $1 \mathrm{mg} \mathrm{V} / \mathrm{d}$.

(4) Diabetic group treated with $3 \mathrm{mg} \mathrm{V} / \mathrm{d}$ (DMVH): ten rats fed the semi-synthetic diet AIN-93. Diabetes was induced in rats by the injection of STZ at a dose of $60 \mathrm{mg} / \mathrm{kg}$. In addition, the rats in this group received in their drinking water $18.66 \mathrm{mg} \mathrm{BMOV/d}$, which supplied $3 \mathrm{mg} \mathrm{V} / \mathrm{d}$.

In all cases, the BMOV solution was prepared daily. During the experimental period, the weight gain and the intake of food and water were monitored. Every $7 \mathrm{~d}$, the glucose level in the peripheral blood was analysed.

On day 35, rats were anaesthetised with a solution of pentobarbital ( $0.5 \mathrm{~g} / 100 \mathrm{ml}$; Sigma-Aldrich, St Louis, MO, USA), and exsanguinated by cannulating the posterior aorta. Blood was collected and centrifuged (Beckman Coulter, Fullerton, CA, USA) at $3000 \mathrm{rpm}$ for $15 \mathrm{~min}$ to separate serum. The gastrocnemius muscle, kidney, liver and spleen were also removed, weighed, placed in preweighed polyethylene vials and stored at $-80^{\circ} \mathrm{C}$. During the last $7 \mathrm{~d}$ of the experimental period, the faeces and urine were collected every $24 \mathrm{~h}$ and stored at $-80^{\circ} \mathrm{C}$ in polyethylene bottles for subsequent analysis.

All animals were housed from day 0 of the experiment in individual metabolism cages designed for the separate collection of faeces and urine. The cages were located in a wellventilated, temperature-controlled room $\left(21 \pm 2{ }^{\circ} \mathrm{C}\right)$ with relative humidity ranging from 40 to $60 \%$, and a light-dark period of $12 \mathrm{~h}$.

The following biological indices were calculated: absorbed as $(I-F)$, absorption (\%) as $((I-F) / I) \times 100$, retained as $(I-(F+U))$ and retained $(\%) R / I$ as $(I-(F+U)) / I \times 100$, where $I$ is the intake; $F$ is the faecal excretion; $U$ is the urinary excretion.

All experiments were carried out in accordance with Directional Guides Related to Animal Housing and Care (European Council Community, 1986) and all procedures were approved by the Animal Experimentation Ethics Committee of the University of Granada.

\section{Analytical methods}

Determination of $\mathrm{V}$ and Se in the diet, serum and tissues was performed using inductively coupled plasma spectroscopyMS (Agilent 7500; Agilent Technologies, Tokyo, Japan). All materials used in the analysis were previously cleaned with super-pure $\mathrm{HNO}_{3}$ and ultra-pure water (18.2 $\Omega$ ) obtained using a Milli Q system (Millipore, Bedford, MA, USA).

Samples were prepared by digestion with $\mathrm{HNO}_{3}$ and $\mathrm{H}_{2} \mathrm{O}_{2}$ (super-pure quality; Merck, Darmstadt, Germany), in a microwave digester (Milestone, Sorisole, Italy). When the sample had been digested, the extract was collected and made up to a final volume of $10 \mathrm{ml}$ for subsequent analysis.

Calibration curves were prepared following the Ga addition technique as an internal standard, using stock solutions of $1000 \mathrm{mg} / \mathrm{l}$ of each element (Merck).

The total metal content ( $\mathrm{V}$ and $\mathrm{Se}$ ) in the tissues was analysed using inductively coupled plasma spectroscopy-MS techniques $^{(9)}$, and the accuracy of the method was evaluated by the analysis of suitable certified reference materials, Seronorm (Billingstad, Norway) and NIST 8414 (Gaithersburg, MD, USA), and by recovery studies in samples of organs enriched with multi-element standards. The percentage of CV obtained for Se was $2.9 \%$ and that for V 5.6\%. For each element, we used the mean of five separate determinations of this reference material.

Glycaemia levels were determined using the sensor ACCUCHEK AVIVA (Roche, Mannheim, Germany). Plasma levels of 
insulin were determined using the SPI BIO (Montigny le Bretonneux, France) enzyme immune assay technique.

Total antioxidant status (TAS) was determined using a Randox ${ }^{\circledR}$ assay kit (Randox Laboratories Limited, Crumlin, Antrim, UK). The assay is based on the incubation of $2,2^{\prime}-$ azino-di-(3-ethylbenzthiazoline-6-sulfonic acid) (ABTS) with a peroxidase (methmyoglobin) and $\mathrm{H}_{2} \mathrm{O}_{2}$ to produce the radical cations $\mathrm{ABTS}^{+}$, which has a relatively stable blue-green colour, measured at $600 \mathrm{~nm}$. The suppression of the colour is compared with that of Trolox, which is widely used as a traditional standard for TAS measurement assays, and the assay results are expressed as Trolox equivalent ( $\mathrm{nmol} / \mathrm{l}$ ).

Liver samples were homogenised in ice-cold buffer (100 mm-Tris-HCl, $0 \cdot 1 \mathrm{~mm}$-EDTA and $0 \cdot 1 \%$ Triton $\mathrm{X}-100$ $(\mathrm{v} / \mathrm{v}), \mathrm{pH} 7 \cdot 8)$ at a ratio of 1:9 (w/v). Homogenates were centrifuged at $30000 \mathrm{rpm}$ for $30 \mathrm{~min}$ in a Centrikon $\mathrm{H}-401$ (Kontron Hermle, Zurich, Switzerland) centrifuge. After centrifugation, the supernatant was collected and frozen at $-80^{\circ} \mathrm{C}$ until analysed.

All enzymatic assays were carried out at $25 \pm 0 \cdot 5^{\circ} \mathrm{C}$ using a PowerWavex microplate scanning spectrophotometer (Bio-Tek Instruments, Winooski, VT, USA) in duplicate in ninety-six-well microplates (UVStar ${ }^{\circledR}$; Greiner Bio-One, Frickenhausen, Germany). The enzymatic reactions were started by the addition of the tissue extract. The specific assay conditions were as follows:

Glutathione peroxidase (GSH-Px; EC 1.11.1.9) activity was measured following the method of Flohé \& Günzler ${ }^{(10)}$ with some modifications ${ }^{(11)}$. A freshly prepared glutathione reductase (GR) solution ( $40 \mu \mathrm{kat} / 1$ in $0 \cdot 1 \mathrm{M}$-potassium phosphate buffer, $\mathrm{pH} 7 \cdot 0$ ) was added to a $50 \mathrm{~mm}$-potassium phosphate buffer ( $\mathrm{pH} 7 \cdot 0$ ), 0.5 mm-EDTA, 1 mm-sodium azide, $0 \cdot 15 \mathrm{~mm}-\mathrm{NADPH}$ and $0 \cdot 15 \mathrm{~mm}$-cumene hydroperoxide. After the addition of $1 \mathrm{~mm}$ - reduced glutathione (GSH), the NADPH consumption rate was monitored at $340 \mathrm{~nm}$.

GR (EC 1.6.4.2) activity was assayed as described by Carlberg \& Mannervik ${ }^{(12)}$ with some modifications ${ }^{(11)}$, by measuring the oxidation of NADPH at $340 \mathrm{~nm}$. The reaction mixture consisted of $0 \cdot 1 \mathrm{~m}$-sodium phosphate buffer ( $\mathrm{pH} 7 \cdot 5), 1 \mathrm{mm-EDTA}$, $0.63 \mathrm{~mm}-\mathrm{NADPH}$ and $0.15 \mathrm{~mm}$-oxidised glutathione.

Glutathione transferase (GST; EC 2.5.1.18) activity was determined by the method of Habig et al. ${ }^{(13)}$ adapted to a microplate reader $^{(14)}$. The reaction mixture consisted of $0 \cdot 1 \mathrm{M}$-phosphate buffer (pH 6.5), 1.2 mm-GSH and 1.23 mm-solution of 1-chloro2,4-dinitrobenzene in ethanol, all prepared just before the assay. GST activity was monitored at $340 \mathrm{~nm}$ by the formation of glutathione-chloro-dinitro benzene conjugate.

For these enzymes, one unit of activity is defined as the amount of enzyme required to transform $1 \mu \mathrm{mol}$ of substrate/min under the above assay conditions. The protein content of the supernatant solutions was determined by the Bradford method ${ }^{(15)}$, using bovine serum albumin as the standard.

Lipid peroxidation levels were determined based on malondialdehyde (MDA) levels generated by the oxidation of PUFA. In the presence of thiobarbituric acid, MDA reacts to produce coloured thiobarbituric-acid-reacting substances that were measured at $535 \mathrm{~nm}$, following Buege \& Aust ${ }^{(16)}$.
The percentage of CV for GSH-Px, GR, GST and MDA was $7 \cdot 3,5.5,6.4$ and $8 \cdot 5 \%$, respectively. For each enzyme, we used the mean of five separate determinations of the same liver sample from a control rat.

All biochemicals, including substrates, coenzymes and purified enzymes, were obtained from Roche or Sigma Chemical Company. All other chemicals came from Merck and were of reagent grade.

\section{Statistical analysis}

Descriptive statistical parameters (means and standard deviations) were obtained for each of the variables studied. The MannWhitney $U$ test for two independent samples and the KruskalWallis test for multiple independent samples were used in the analyses. For the bivariate analysis, Spearman's coefficient of correlation was calculated. All analyses were performed using SPSS 15.0 (SPSS, Chicago, IL, USA). Differences were considered statistically significant at a probability level $<5 \%$.

\section{Results}

Table 1 shows the evolution of the mean body weight and mean food intake of rats during the experimental period. The diabetic STZ rats (DM) did not present a significant change in body weight during the experimental period. Treatment with $\mathrm{V}$, both at $1 \mathrm{mg} \mathrm{V} / \mathrm{d}$ (DMV) and at $3 \mathrm{mg} \mathrm{V} / \mathrm{d}$ (DMVH), induced weight changes similar to those observed in the DM rats.

Diabetes increased the food intake. However, the higherdose $\mathrm{V}$ treatment reduced the food intake of rats, to levels slightly below those of the control rats (Table 1 ).

Table 2 shows the evolution of fasting glycaemia during the experimental period. The $\mathrm{V}$ treatment of $1 \mathrm{mg} / \mathrm{d}$ did not significantly alter glycaemia levels in the diabetic rats during the first $28 \mathrm{~d}$. However, on day 35 , glycaemia levels were higher than those in the DM group. The treatment with the $3 \mathrm{mg} \mathrm{V} / \mathrm{d}$ dose maintained glycaemia at levels similar to those of the control rats.

Table 1. Evolution of mean body weight and mean food intakes during the experimental period

(Mean values with their standard errors)

\begin{tabular}{|c|c|c|c|c|c|c|}
\hline \multirow[b]{3}{*}{ Groups } & \multicolumn{6}{|c|}{ Body weight (g) } \\
\hline & \multicolumn{2}{|c|}{ Day 0} & \multicolumn{2}{|c|}{ Day 35} & \multicolumn{2}{|c|}{ Food intake (g) } \\
\hline & Mean & SE & Mean & SE & Mean & SE \\
\hline C & 200 & 5 & 296 & 10 & $15 \cdot 5$ & 0.4 \\
\hline DM & $184^{\star *}$ & 7 & $201^{\star *}$ & 15 & $30 \cdot 1^{\star \star \star}$ & 0.9 \\
\hline DMV & $187^{\star}$ & 3 & $181^{\star \star \star}$ & 3 & $22 \cdot 6^{* * *}+\dagger \dagger$ & 1.2 \\
\hline DMVH & 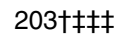 & 1 & $204^{\star * \star} \ddagger$ & 8 & $11 \cdot 6^{\star \star \star}$ †††㧊 & 0.4 \\
\hline
\end{tabular}

C, control rats; DM, diabetic streptozotocin rats; DMV, diabetic streptozotocin rats treated with $1 \mathrm{mg} \mathrm{V/d}$; DMVH, diabetic streptozotocin rats treated with $3 \mathrm{mg} \mathrm{V/d}$. Mean value was significantly different from that of the $C$ group: ${ }^{\star} P<0.05$, ${ }^{\star \star} P<0.01$, ${ }_{* \star *} P<0.001$.

Mean value was significantly different from that of the DM group: $† P<0.05$ ††† $P<0.001$.

Mean value was significantly different from that of the DMV group: $\ddagger P<0.05$,

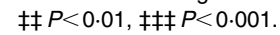


Table 2. Fasting glycaemia during the experimental period $(\mathrm{mmol} / \mathrm{l})$

(Mean values with their standard errors)

\begin{tabular}{|c|c|c|c|c|c|c|c|c|c|c|c|c|}
\hline \multirow[b]{2}{*}{ Groups } & \multicolumn{2}{|c|}{ Day 0} & \multicolumn{2}{|c|}{ Day 7} & \multicolumn{2}{|c|}{ Day 14} & \multicolumn{2}{|c|}{ Day 21} & \multicolumn{2}{|c|}{ Day 28} & \multicolumn{2}{|c|}{ Day 35} \\
\hline & Mean & SE & Mean & SE & Mean & SE & Mean & $\mathrm{SE}$ & Mean & SE & Mean & SE \\
\hline C & $3 \cdot 6$ & 0.4 & $5 \cdot 0$ & 0.3 & $5 \cdot 7$ & 0.1 & $5 \cdot 1$ & 0.2 & $5 \cdot 2$ & 0.1 & 4.7 & 0.3 \\
\hline DM & $7 \cdot 9^{\star \star}$ & 1.3 & $13 \cdot 9^{\star \star}$ & $2 \cdot 1$ & $13 \cdot 6^{\star *}$ & $1 \cdot 1$ & $14 \cdot 3^{\star \star}$ & 1.9 & $14 \cdot 2^{\star \star}$ & 2.0 & $14 \cdot 6^{\star *}$ & 1.2 \\
\hline DMV & $11 \cdot 6^{\star \star}$ & 1.9 & $17 \cdot 0^{\star \star}$ & $2 \cdot 0$ & $16 \cdot 0^{\star *}$ & 1.8 & $16 \cdot 0^{\star \star}$ & $2 \cdot 2$ & $12 \cdot 5^{\star \star}$ & 1.5 & $19 \cdot 6^{\star \star \star} \dagger$ & 1.7 \\
\hline DMVH & $9 \cdot 4^{\star *}$ & 1.2 & 5.0†十㧊 & 0.3 & $4 \cdot 7^{\star}$ ††キ & 0.1 & 5.4†††‡ & 0.3 & 5.1†十市 & 0.3 & 5.3†十㧊 & 0.3 \\
\hline
\end{tabular}

$\mathrm{C}$, control rats; DM, diabetic streptozotocin rats; DMV, diabetic streptozotocin rats treated with $1 \mathrm{mg} \mathrm{V} / \mathrm{d}$; DMVH, diabetic streptozotocin rats treated with $3 \mathrm{mg} \mathrm{V} / \mathrm{d}$. Mean value was significantly different from that of the $C$ group: ${ }^{*} P<0.05,{ }^{\star \star} P<0.01,{ }^{\star \star \star} P<0.001$.

Mean value was significantly different from that of the DM group: $\dagger P<0.05, \dagger \dagger P<0.01$.

Mean value was significantly different from that of the DMV group: $\ddagger \ddagger P<0.01$, $\ddagger \ddagger \ddagger P<0.001$

Table 3 shows serum V, Se and insulin on day 35, in the experimental groups. Diabetes induced by STZ produced a significant increase in the serum levels of $\mathrm{V}$ and $\mathrm{Se}$ and a decrease in circulating insulin. The diabetic rats treated with $1 \mathrm{mg} \mathrm{V} / \mathrm{d}$ did not present any change in serum Se or insulin, compared with the untreated diabetic rats. However, the diabetic rats treated with $3 \mathrm{mg} \mathrm{V} / \mathrm{d}$ presented serum Se values below those of the control rats, while insulin and TAS remained at levels similar to those of the diabetic rats.

Table 4 shows the digestive and metabolic utilisation of Se. Diabetes (DM group) increases the net values of absorbed and retained Se; although when expressed as a percentage ( $\%$ absorption and $\% \mathrm{R} / \mathrm{I}$ ), no significant changes were observed. The diabetic rats treated with $1 \mathrm{mg} \mathrm{V} / \mathrm{d}$ (DMV) presented a reduction in Se absorption and Se retained, in comparison with the DM group.

Table 5 shows the Se content in the muscle, kidney, liver and spleen on day 35. Diabetes increased Se content in the kidney, liver, spleen and heart. In the diabetic rats, the $\mathrm{V}$ treatment, at a dose of $1 \mathrm{mg} \mathrm{V} / \mathrm{d}$, decreased Se content in the liver and spleen in comparison with the untreated diabetic rats (DM), but these values remained higher than those of the control rats, except in the case of the muscle and spleen. The treatment of the diabetic rats with $3 \mathrm{mg} \mathrm{V} / \mathrm{d}$ produced a significant reduction in Se in the kidney, liver and spleen.

TAS and the activities of GSH-Px, GR, GST and lipid peroxidation levels (MDA) are shown in Table 6. The treatment leads to a decrease in the activity of GSH-Px and GST and an increase in the lipid peroxidation level.

The bivariate study revealed the existence of significant relationships, among which the following are particularly important: $\mathrm{V}$ intake correlated negatively with Se absorbed $(r-0.556 ; P<0.01)$, Se retained $(r-0.644 ; P<0.001)$, GSHPx $(r-0.414 ; P<0.05)$ and GST $(r-0.817 ; P<0.001)$ activity, and positively with MDA $(r 0.388 ; P<0.05)$.

Se intake correlated positively with Se content in the kidney ( $r$ 0.790; $P<0.001)$, liver $(r 0.840 ; P<0.001)$, spleen $(r$ 0.593; $P<0.001)$ and heart $(r 0.529 ; P<0.01)$. Se absorbed correlated positively with the serum levels of Se $(r 0.870 ; P<0.001)$, Se content in the kidney $(r$ 0.876; $P<0.001)$, liver $(r$ 0.880; $P<0.001)$, spleen $(r 0.664 ; P<0.001)$ and heart $(r 0.420$; $P<0.05)$. Se content in the liver correlated positively with GSH-PX $(r \quad 0.941 ; \quad P=0.001)$ and negatively with MDA $(r-0.529 ; P<0.01)$.

\section{Discussion}

Diabetes is a pathology that affects the metabolism of various trace elements and the activity of enzymes related to antioxidant defence. This circumstance may contribute to the development of the disease. It has been shown that $\mathrm{V}$ is a trace element associated with the regulation of glucose, improving its transport and metabolism and increasing the sensitivity of the insulin receptor ${ }^{(1)}$. However, there are many aspects that remain to be determined, such as the interactions with other elements.

In view of the lack of information on $\mathrm{Se}-\mathrm{V}$ interactions, the present study examines diabetic rats treated with different doses of $\mathrm{V}$ in order to determine Se bioavailability and tissue distribution, and its relationship to some indicators of the nutritional status of this element. Based on the study results, under our experimental conditions, the $\mathrm{V}$ treatment

Table 3. Fasting selenium, vanadium and insulin in serum on day 35

(Mean values with their standard errors)

\begin{tabular}{|c|c|c|c|c|c|c|c|c|c|}
\hline \multirow[t]{2}{*}{ Groups... } & \multicolumn{2}{|c|}{$\mathrm{C}$} & \multicolumn{2}{|c|}{ DM } & \multicolumn{2}{|c|}{ DMV } & \multicolumn{2}{|l|}{ DMVH } & \multirow[b]{2}{*}{$P_{\mathrm{K}-\mathrm{W} \text { tes }}$} \\
\hline & Mean & SE & Mean & SE & Mean & SE & Mean & SE & \\
\hline Serum V $(\mu \mathrm{mol} / \mathrm{l})$ & 0.045 & 0.004 & $0.12^{\star \star}$ & 0.009 & $7 \cdot 5^{\star *}+\dagger$ & 0.7 & 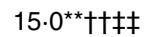 & 1.5 & $<0.001$ \\
\hline Serum Se $(\mu \mathrm{mol} / \mathrm{l})$ & 1.03 & 0.03 & $1 \cdot 15^{\star \star}$ & 0.03 & $1 \cdot 49^{\star \star}$ & 0.06 & 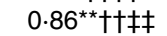 & 0.04 & $<0.001$ \\
\hline Serum insulin (pmol/l) & 313 & 40 & $38^{\star \star}$ & 9 & $41^{\star \star}$ & 12 & $34^{\star *}$ & 3 & $<0.001$ \\
\hline
\end{tabular}

${ }^{\star \star}$ Mean value was significantly different from that of the $C$ group $(P<0.01)$. †† Mean value was significantly different from that of the DM group $(P<0.01)$. $\ddagger \ddagger$ Mean value was significantly different from that of the DMV group $(P<0.01)$. 
Table 4. Digestive and metabolic utilisation of selenium on days $28-35$ of the study (Mean values with their standard errors)

\begin{tabular}{|c|c|c|c|c|c|c|c|c|c|}
\hline \multirow[t]{2}{*}{ Groups... } & \multicolumn{2}{|c|}{$C(n 9)$} & \multicolumn{2}{|c|}{$\mathrm{DM}(n 8)$} & \multicolumn{2}{|c|}{$\mathrm{DMV}(n 8)$} & \multicolumn{2}{|c|}{ DMVH $(n 8)$} & \multirow[b]{2}{*}{$P_{\mathrm{K}-\mathrm{W} \text { tes }}$} \\
\hline & Mean & SE & Mean & SE & Mean & SE & Mean & SE & \\
\hline$I(\mu \mathrm{g} / \mathrm{d})$ & 0.99 & 0.04 & $2 \cdot 18^{\star \star \star}$ & 0.06 & $1.77^{\star \star \star}+\dagger \dagger$ & 0.04 & 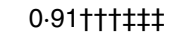 & 0.03 & $<0.01$ \\
\hline$F(\mu \mathrm{g} / \mathrm{d})$ & 0.20 & 0.03 & $0.39^{\star \star}$ & 0.06 & $0.37^{\star \star}$ & 0.04 & $0.54^{\star \star \star} \ddagger$ & 0.06 & $<0.001$ \\
\hline$U(\mu \mathrm{g} / \mathrm{d})$ & 0.26 & 0.02 & $0.59^{\star \star \star}$ & 0.07 & $0.63^{\star \star \star}$ & 0.04 & $0 \cdot 17^{*}$ ††㧊 & 0.01 & $<0.001$ \\
\hline$A=(I-F)(\mu \mathrm{g} / \mathrm{d})$ & 0.79 & 0.05 & $1.80^{\star * *}$ & 0.05 & $1.40^{\star \star \star}+† \dagger$ & 0.04 & 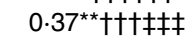 & 0.07 & $<0.001$ \\
\hline$A(\%)=(A / I) \times 100$ & 80 & 3 & 82 & 2 & 79 & 2 & 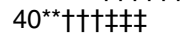 & 7 & $<0.001$ \\
\hline$R=(I-(F+U)(\mu \mathrm{g} / \mathrm{d})$ & 0.53 & 0.05 & $1 \cdot 20^{\star \star \star}$ & 0.06 & $0.76^{\star \star}+\dagger \dagger$ & 0.06 & 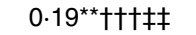 & 0.07 & $<0.001$ \\
\hline$R(\%)=(R / I) \times 100$ & 53 & 4 & 56 & 4 & $43^{*} \dagger$ & 3 & $21^{\star \star} \dagger † \ddagger$ & 7 & $<0.01$ \\
\hline
\end{tabular}

$\mathrm{C}$, control rats; DM, diabetic streptozotocin rats; DMV, diabetic streptozotocin rats treated with $1 \mathrm{mg} \mathrm{V} / \mathrm{d}$; DMVH, diabetic streptozotocin rats treated with $3 \mathrm{mg}$

$\mathrm{V} / \mathrm{d}$; $I$, intake; $F$, faecal excretion; $U$, urinary excretion; $A$, absorbed; $R$, retained.

Mean value was significantly different from that of the $C$ group: ${ }^{\star} P<0.05,{ }^{\star \star} P<0.01,{ }^{\star \star \star} P<0.001$

Mean value was significantly different from that of the DM group: $\uparrow P<0.05, \dagger \dagger P<0.01, \dagger+\uparrow P<0.001$.

Mean value was significantly different from that of the DMV group: $\ddagger P<0.05, \ddagger \ddagger P<0.01, \ddagger \ddagger \ddagger P<0.001$.

caused a tissue depletion of Se that compromised Se nutritional status and antioxidant defences in the tissues

The doses of $\mathrm{V}$ used in the present study $(1 \mathrm{mg} \mathrm{V} / \mathrm{d}$ approximately $5 \mathrm{mg} \mathrm{V} / \mathrm{kg}$ body weight per $\mathrm{d}$ and $3 \mathrm{mg} \mathrm{V} / \mathrm{d}$ approximately $15 \mathrm{mg} \mathrm{V} / \mathrm{kg}$ body weight per $\mathrm{d}$ ) are higher than the lowest dose reported to cause adverse effects in rats $(0.8 \mathrm{mg}$ $\mathrm{V} / \mathrm{kg}$ body weight per $\mathrm{d}$ ). However, the doses used are low in comparison with those used in other studies and much lower than LD50 (lethal close 50) (40-90 mg V/kg body weight per $\mathrm{d})^{(17)}$. In each group treated with $\mathrm{V}$, two rats (20\%) were removed from the present study due to gastrointestinal disorders.

In the untreated diabetic rats (DM), there were no significant weight increases during the experimental period, due to the hypercatabolism that accompanies the disease, although the rats presented polyphagia. The diabetic rats treated with $\mathrm{V}$ did not present significant weight changes ${ }^{(4)}$, although food intake did significantly decrease as the $\mathrm{V}$ dose was increased, reaching values similar to those of the control rats in the case of the dose of $3 \mathrm{mg} \mathrm{V} / \mathrm{d}$. It has been suggested that the decrease in food intake could be because $\mathrm{V}$ heightens the catabolic effects of leptin, favouring body-weight loss and reducing food intake ${ }^{(18)}$.

The V treatment of $1 \mathrm{mg} / \mathrm{d}$ (DMV) did not significantly alter glycaemia levels in the diabetic rats during the first $28 \mathrm{~d}$. The higher levels of glycaemia observed on day 35 in the DMV group, with respect to the DM group, could be because STZ produced more severe pancreatic damage in some rats, and this circumstance was apparent at the end of the experimental period.

The dose of $3 \mathrm{mg} \mathrm{V} / \mathrm{d}$ normalised glycaemia levels in the diabetic rats, from the first week of the treatment. These results coincide with those reported earlier ${ }^{(19-21)}$. Nevertheless, other authors have observed that although $\mathrm{V}$ exercises a hypoglycaemic effect, normal glycaemia levels are not achieved $^{(3,4,22,23)}$. This inconsistency could be due to various factors, such as the use of different compounds and doses of $\mathrm{V}$, the duration of assays, the method employed to determine glucose levels, the dose of STZ used and/or variability in the animals' responses.

The diabetic rats presented a level of insulinaemia that was well below that observed in the control rats, due to the destruction of $\beta$-cells caused by STZ. Treatment with V, independently of the dose applied, had no effect on the serum levels of insulin (Table 3).

Serum levels of Se in the DM group were higher than those in the control group, because the animals in the DM group consumed more food, which led to increases in the net quantities of Se absorbed and retained (Table 4). The increased body retention of se caused by diabetes is assumed to be responsible for the increased serum levels and the content of Se in the tissues of the diabetic rats (Table 5). The correlations found between Se intake and its content in the tissues (see the Results section) corroborate this hypothesis.

The treatment of the diabetic rats with $1 \mathrm{mg} \mathrm{V} / \mathrm{d}$ (DMV group) had no effect on fasting glycaemia, but in comparison

Table 5. Selenium content in muscle, kidney, liver, spleen, heart, adipose tissue and femur ( $\mathrm{mg} / \mathrm{kg}$ dry tissue) on day 35 (Mean values with their standard errors)

\begin{tabular}{|c|c|c|c|c|c|c|c|c|c|}
\hline \multirow[t]{2}{*}{ Groups... } & \multicolumn{2}{|c|}{$\mathrm{C}$} & \multicolumn{2}{|c|}{ DM } & \multicolumn{2}{|c|}{ DMV } & \multicolumn{2}{|l|}{ DMVH } & \multirow[b]{2}{*}{$P_{\mathrm{K}-\mathrm{W} \text { test }}$} \\
\hline & Mean & SE & Mean & SE & Mean & SE & Mean & SE & \\
\hline Gastrocnemius muscle & 0.43 & 0.02 & 0.47 & 0.02 & 0.44 & 0.01 & 0.42 & 0.02 & $>0.05$ \\
\hline Kidney & 4.62 & 0.17 & $6 \cdot 11^{\star * *}$ & 0.14 & $5 \cdot 71^{* *}$ & 0.14 & 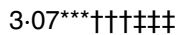 & 0.09 & $<0.001$ \\
\hline Liver & $2 \cdot 38$ & 0.11 & $3.73^{\star \star \star}$ & 0.15 & $3 \cdot 01^{\star \star} \dagger \dagger$ & 0.09 & 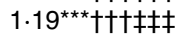 & 0.01 & $<0.001$ \\
\hline Spleen & 1.54 & 0.04 & $1 \cdot 76^{\star}$ & 0.06 & $1.54 \dagger$ & 0.06 & $1 \cdot 31^{\star *}+† † \ddagger$ & 0.07 & $<0.01$ \\
\hline
\end{tabular}

$\mathrm{C}$, control rats; DM, diabetic streptozotocin rats; DMV, diabetic streptozotocin rats treated with $1 \mathrm{mg} \mathrm{V} / \mathrm{d}$; DMVH, diabetic streptozotocin rats treated with $3 \mathrm{mg}$ V/d. Mean value was significantly different from that of the $C$ group: ${ }^{\star} P<0.05,{ }^{\star \star} P<0.01,{ }^{\star \star \star} P<0.001$.

Mean value was significantly different from that of the DM group: $\dagger P<0.05, \dagger \dagger P<0.01 \dagger \dagger \dagger P<0.001$.

Mean value was significantly different from that of the DMV group: $\ddagger P<0.05, \ddagger \ddagger \ddagger P<0.001$. 
Table 6. Total antioxidant status (TAS) in serum and activity of glutathione peroxidase (GSH-Px); glutathione reductase (GR) and glutathione transferase (GST), and malondialdehyde (MDA) levels in the liver on day 35

(Mean values with their standard errors)

\begin{tabular}{|c|c|c|c|c|c|c|c|c|c|}
\hline \multirow[t]{2}{*}{ Groups... } & \multicolumn{2}{|c|}{ C } & \multicolumn{2}{|c|}{ DM } & \multicolumn{2}{|c|}{ DMV } & \multicolumn{2}{|c|}{ DMVH } & \multirow[b]{2}{*}{$P_{\mathrm{K}-\mathrm{W} \text { test }}$} \\
\hline & Mean & SE & Mean & SE & Mean & SE & Mean & SE & \\
\hline TAS (mmol/l) & 1.29 & 0.08 & $0.91^{*}$ & 0.08 & $0.95^{*}$ & 0.07 & $0.86^{*}$ & 0.10 & $<0.01$ \\
\hline GSH-Px ( $\mu$ kat/g protein) & $10 \cdot 5$ & 0.9 & $19 \cdot 2^{\star \star *}$ & 0.6 & $14 \cdot 4^{*}+\dagger$ & $1 \cdot 0$ & 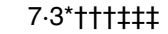 & $1 \cdot 0$ & $<0.001$ \\
\hline GR ( $\mu$ kat/g protein) & 0.57 & 0.05 & 0.55 & 0.01 & 0.55 & 0.01 & 0.53 & 0.02 & $>0.05$ \\
\hline GST ( $\mu$ kat $/ g$ protein) & 4.68 & 0.05 & $4 \cdot 10^{\star *}$ & 0.12 & $3 \cdot 67^{\star \star \star}$ & 0.12 & $3 \cdot 48^{\star \star \star}+\dagger$ & 0.12 & $<0.001$ \\
\hline MDA (nmol/g liver) & 48 & 4 & 42 & 3 & 49 & 2 & $62^{*}+† \ddagger$ & 4 & $<0.05$ \\
\hline
\end{tabular}

$\mathrm{C}$, control rats; DM, diabetic streptozotocin rats; DMV, diabetic streptozotocin rats treated with $1 \mathrm{mg}$ V/d; DMVH, diabetic streptozotocin rats treated with $3 \mathrm{mg} \mathrm{V} / \mathrm{d}$.

Mean value was significantly different from that of the $C$ group: ${ }^{*} P<0.05,{ }^{\star \star} P<0.01,{ }^{\star \star *} P<0.001$

Mean value was significantly different from that of the DM group: $+\dagger P<0.01,+\dagger+P<0.001$.

Mean value was significantly different from that of the DMV group: $\ddagger P<0.05, \ddagger \ddagger \ddagger P<0.001$.

with the untreated diabetic rats, there was a decrease in food intake and in the net quantities of Se absorbed and retained. In our opinion, the lower absorption and retention of Se in the DMV group appears to respond to the changes in food intake produced by the treatment. The reduced Se retention is responsible for the slight decrease in Se content in the liver and spleen.

The dose of $3 \mathrm{mg} \mathrm{V} / \mathrm{d}$ given to the diabetic rats (DMVH group) had a clearly anti-diabetic effect, normalising glycaemia levels and reducing food intake to levels similar to those of the controls. Moreover, this dose of $\mathrm{V}$ produced a severe reduction in the absorption and urinary losses of Se. We believe that the main cause of the drastic reduction in absorbed Se may be due to reduced Se intake (Table 3). Nevertheless, the high concentration of $\mathrm{V}$ in the intestine could also have interfered with Se absorption ${ }^{(24,25)}$. The negative correlations found between the intake of $\mathrm{V}$ and the absorbed Se (see the Results section) corroborate the above remarks.

The reduction in the urinary losses of Se could be a compensatory mechanism to avoid its depletion. Under physiological conditions, the homoeostasis of Se is basically regulated by urinary excretion ${ }^{(7,26)}$.

We believe that in the DMVH group, the reduced absorption is responsible for the lower Se content in serum (Table 3) and in the kidney, liver and spleen (Table 5).

In order to better determine whether Se tissue depletion had affected the oxidative status, we designed a study of serum TAS and of the activity of three GSH-dependent enzymes: GSH-Px and hepatic GR and GST.

The present results show that in the untreated diabetic rats, serum TAS decreased, while in the liver, the activity of GSH-Px increased, that of GR remained unchanged and that of GST diminished (Table 6). The increased GSH-Px activity could be related to the greater content of hepatic Se found in this group. Hepatic GSH-Px is known to be very effective in determining the nutritional status of $\mathrm{Se}^{(27)}$ (Table 5). An earlier publication has reported lower levels of GSH in the erythrocytes of diabetic patients ${ }^{(28)}$. In the present study conditions, the degradation of GSH would account for the reduced activity of GST found in this group.
The $\mathrm{V}$ treatment given to the diabetic rats did not affect TAS (Table 6), irrespective of the dose. Other authors, in previous studies $^{(29)}$, have observed no significant changes in TAS following the $\mathrm{V}$ treatment.

It has been reported that exposure to $\mathrm{V}$ results in the depletion of the cellular GSH pool, which increases the vulnerability to lipid peroxidation ${ }^{(30-32)}$. The results obtained in the present study show that the $\mathrm{V}$ treatment to the diabetic rats at $1 \mathrm{mg} \mathrm{V} / \mathrm{d}$ does not modify glycaemia, but does produce slight decreases in food intake, Se absorbed and Se in the liver and spleen. The depletion of Se in the liver is accompanied by a reduction in the activity of GSH-Px and a non-significant increase in MDA, compared with the untreated diabetic rats. The treatment at $3 \mathrm{mg} \mathrm{V} / \mathrm{d}$ induced a clearly anti-diabetic effect, as both food intake and glycaemia levels were normalised. In addition, there was a sharp decrease in Se absorption and Se content in various tissues. The strong depletion of Se in the liver (Table 5) could account for the reduced activity of GSH-Px. Studies ${ }^{(4,31)}$ have reported that the depletion of GSH could account for the reduced activity of GST and also contribute to that of GSH-Px. The lower levels of activity of these enzymes could be related to the higher levels of MDA. Bivariate analysis reveals a high positive correlation between the liver content of Se and the activity of GSH-Px, together with a negative correlation with MDA (see the Results section). We conclude that under our experimental conditions, the $\mathrm{V}$ treatment caused a tissue depletion of Se that compromised Se nutritional status and antioxidant defences in the tissues. However, further studies are needed to better determine the effects arising from these interactions.

\section{Acknowledgements}

The authors are grateful for support received from the Consejería de Innovacion, Ciencia y Empresa, Andalusian Regional Government (project P06-CTS-01435). All authors have made substantial contributions to all of the following: the conception and design of the study, or acquisition of the data, or analysis and interpretation of the data; drafting the manuscript or revising it critically for important intellectual content; final approval of the version to be submitted. There are no 
conflicts of interest of authors or consortium members, since this study was funded by public funds. This study is dedicated to basic research and there are no commercial interests.

\section{References}

1. Thompson KH \& Orvig C (2006) Vanadium in diabetes: 100 years from Phase 0 to Phase I. J Inorg Biochem 100, $1925-1935$

2. Kawabe K, Yoshikawa Y, Adichi, et al. (2006) Possible mode of action for insulinomimetic activity of vanadyl(IV) compounds in adipocytes. Life Sci 78, 2860-2866.

3. Yanardag R \& Tunail S (2006) Vanadyl sulphate administration protects the streptozotocin-induced oxidative damage to brain tissue in rats. Mol Cell Biochem 286, 153-159.

4. Oster MH, Llobet JM, Domingo LJ, et al. (1993) Vanadium treatment of diabetic Sprague-Dawley rats results in tissue vanadium accumulation and pro-oxidant effects. Toxicology 83, 115-130.

5. Wiernsperger N \& Rapin JR (2010) Trace elements in glucometabolic disorders: an update. Diabetol Metab Syndr 2, 70-75.

6. Xu TJ, Yuan BX, Zou YM, et al. (2010) The effect of insulin in combination with selenium on blood glucose and GLUT4 expression in the cardiac muscle of streptozotocin-induced diabetic rats. Fundam Clin Pharmacol 24, 199-204.

7. Navarro-Alarcón M \& Cabrera-Vique C (2008) Selenium in food and the human body: a review. Sci Total Environ 400, 115-141.

8. Erbayraktar Z, Yilmaz O, Artmann AT, et al. (2007) Effects of selenium supplementation on antioxidant defense and glucose homeostasis in experimental diabetes mellitus. Biol Trace Elem Res 118, 217-226.

9. Del Castillo E, Montes-Bayón M, Añón E, et al. (2008) Simultaneous determination of glycated haemoglobin, a long term biomarker of diabetes mellitus, and total haemoglobin by isotope dilution and HPLC-ICP-MS. J Anal At Spectrom 23, 758-764

10. Flohé L \& Günzler LWA (1984) Assay of glutathione peroxidase. Meth Enzymol 105, 115-121.

11. Trenzado CE, Hidalgo MC, García-Gallego M, et al. (2006) Antioxidant enzymes and lipid peroxidation in sturgeon Acipenser naccarii and trout Oncorhynchus mykiss. A comparative study. Aquaculture 254, 758-767.

12. Carlberg I \& Mannervik B (1975) Purification and characterization of the flavoenzyme glutathione reductase from rat liver. J Biol Chem 250, 5475-5480.

13. Habig WH, Pabst MJ \& Jakoby WB (1974) Glutathione $S$-transferases - the first enzymatic step in mercapturic acid formation. J Biol Chem 249, 7130-7139.

14. Sanz A, Trenzado CE, López-Rodríguez MJ, et al. (2010) Study of antioxidant defense in four species of Perloidea (Insecta, Plecoptera). Zoolog Sci 27, 952-958.

15. Bradford MM (1976) A rapid and sensitive method for the quantification of microgram quantities of protein utilizing the principle of protein dye-binding. Anal Biochem $\mathbf{7 2}$, $248-256$.
16. Buege JA \& Aust SD (1978) Microsomal lipid peroxidation. Meth Enzymol 52, 302-310.

17. EFSA (2004) Opinion of the scientific panel on dietetic products, nutrition and allergies on a request from the commission related to the tolerable upper intake level of vanadium (request no. EFSA-Q-2003-018). EFSA J 33, 1-22. http:// www.efsa.eu.int/

18. Wilsey J, Mantheny MK \& Scarpace PJ (2006) Oral vanadium enhances the catabolic effects of central leptin in young adult rats. Endocrinology 147, 493-501.

19. Majithiya JB, Balaraman R, Giridhar R, et al. (2005) Effect of bis[curcumino]oxovanadium on non-diabetic and streptozotocin-induced diabetic rats. I Trace Elem Med Biol 18 $211-217$.

20. Sun Qian, Sekar N, Goldwaser I, et al. (2000) Vanadate restores glucose-6-phosphate in diabetic rats: a mechanism to enhance glucose metabolism. Am J Physiol Endocrinol Metab 279, 403-410.

21. Cam M, Rodrigues B \& McNeill JH (1999) Distinct glucose lowering and beta cell protective effects of vanadium and food restriction in streptozotocin-diabetes. Eur J Endocrinol 141, 546-554.

22. Facchini DM, Yuen VG, Batell ML, et al. (2006) The effects of vanadium treatment on bone in diabetic and non-diabetic rats. Bone 38, 368-377.

23. Tas S, Sarandol E, Ayvalik SZ, et al. (2007) Vanadyl sulphate, taurine, and combined vanadyl sulphate and taurine treatments in diabetic rats: effects on the oxidative and antioxidative systems. Arch Med Res 38, 276-283.

24. Arduser F, Wolffram S \& Scharrer E (1985) Active absorption of selenate by ileum. J Nutr 115, 1203-1208.

25. Nielsen FH (1996) Other trace elements. Vanadium. In Present Knowledge in Nutrition, pp. 364-370 [EE Ziegler and LJ Filder, editors]. Washington, DC: ILSI Press.

26. Gammelgaard B, Gabel-Jensen C, Stürup S, et al. (2008) Complementary use of molecular and element-specific mass spectrometry for identification of selenium compounds related to human selenium metabolism. Anal Bioanal Chem 390, 1691-1706.

27. Hafeman DG, Sunde RA \& Hoekstra WG (1974) Effect of dietary selenium on erythrocyte and liver glutathione peroxidase in the rat. $J$ Nutr 104, 580-587.

28. Lei XG, Cheng W-H \& McClung JP (2007) Metabolic regulation and function of glutathione peroxidase-1. Ann Rev Nutr 27, 41-61.

29. Scibior A, Zaporowska H, Wolinska A, et al. (2010) Antioxidant enzyme activity and lipid peroxidation in the blood of rats co-treated with vanadium $\left(\mathrm{V}^{+5}\right)$ and chromium $\left(\mathrm{Cr}^{+3}\right)$. Cell Biol Toxicol 26, 509-526.

30. Valko M, Morris H \& Cronin MTD (2005) Metals, toxicity and oxidative stress. Curr Med Chem 12, 1161-1208.

31. Bycczkowski JZ \& Kulkarni AP (1998) Oxidative stress and pro-oxidant biological effects of vanadium. In Vanadium in the Environment. Part 2: Health Effects, pp. 235-264 [JO Nriagu, editor]. New York: John Wiley, Sons, Inc.

32. Cuesta S, Francés D \& García GB (2010) ROS formation and antioxidant status in brain areas of rats exponed to sodium metavanadate. Neurotoxicol Teratol 33, 297-302. 